Endocrinol. Japon. 1985, 32 (6), 881-890

\title{
Oro-Maxillofacial Development in Patients with Turner's Syndrome
}

\author{
Hideki OGIUCHI*, Kazue TAKANO**, Midori TANAKA*, \\ NAOMi HIZUKA**, Shin TAKAGI*, YoshikUni SANGU*, \\ KAZUo SHIZUME**, AND Isshu KAWANISHI* \\ Department of Oral Surgery* and Department of Medicine \\ Institute of Clinical Endocrinology** \\ Tokyo Women's Medical College, \\ 10 Ichigaya Kawadacho, Shinjuku-ku, Tokyo 162
}

\begin{abstract}
Detailed oro-maxillofacial studies using dental casts, pantomograms and cephalograms were performed in 28 patients with Turner's syndrome and compared statistically to the results from 23 normal short children. Small tooth crown size, short tooth roots and advanced dental age were characteristic of patients with Turner's syndrome. However, the incidence of peg shaped teeth, malocclusion, high arched palate and congenital anodontia were not characteristic of patients with Turner's syndrome. The coronal arch width (C.A.W.) and basal arch width (B.A.W.) were greater and the coronal arch length (C.A.L.) and basal arch length (B.A.L.) were less in patient's with Turner's syndrome. These data indicate underdevelopment of the maxilla in the forward direction forming the wide-, flat-shaped facial characteristic of patients with Turner's syndrome.
\end{abstract}

Turner's syndrome is a genetic disorder with many physical abnomalities including short stature, pigmented nevi, webbed neck, cubitus valgus and orofacial abnormalities. Of the possible orofacial abnomalities, triangular face, epicanthic folds, small mandibulla, low-set and malformed ears, higharched palate, and fishlike appearance of the mouth have been reported (Lemli and Smith, 1963; Grumbach and Conte 1981). Early eruption of the permanent teeth, smaller

Received August 1, 1985 than normal permanent teeth and short tooth roots are also reported as characteristic findings in Turner's syndorome (Gorlin 1963; Filipsson et al., 1965; Doner et al., 1967). However, there have been no detailed morphological studies by dental model analysis, pantomograms or cephalograms.

In this paper, we have investigated the oro-maxillofacial development of 28 patients with Turner's syndrome using dental model analysis, pantomograms and cephalograms, and compared the data to those from 23 normal short children. 


\section{Materials and Methods}

\section{Subjects}

Twenty-eight patients aged 9 to 21 years with Turner's syndrome and 23 girls aged 8-14 years of short stature (normal short children) were investigated. The diagnosis of Turner's syndrome was established by sex chromosome analysis. Thirteen patients had the typical 45 XO karyotype. They were all euthyroid. Basal plasma LH (above $16 \mathrm{mIu} / \mathrm{ml}$ ) and FSH (above $9 \mathrm{mIu} / \mathrm{ml}$ ) were elevated in 17 and 22 out of 25 patients examined, respectively. Plasma somatomedin C (SM-C) levels were within the normal range. Normal short children were defined as children with no physical or laboratory abnormalities other than short stature after detailed hormonal examination. Their heights ranged between below 1.0 and 7.0 SD of the mean height of Japanese girls of their own age group, as reported by the Japanese Ministry of Health and Welfare. Eighteen of the patients with Turner's syndrome were treated with biosynthetic methionyl hGH (16 IU/ week) for 3-9 months (Takano et al., 1985). Three other patients with Turner's syndrome (Nos. 8, 12 and 23) and 3 of the normal short children (Nos. 21, 22 and 23) were treated with pituitary hGH (16 IU/week) for 2-3 years. Fourteen patients with Turner's syndrome were treated with a small amount of estrogen (mestranol, $4 \mu \mathrm{g} /$ day) for one year in one (No. 2) and for 1-6 months in the others. Six other patient with Turner's syndrome and 4 of the normal short children were treated with anabolic steroid (stanozol, $1 \mathrm{mg} /$ day) for 7-17 months.
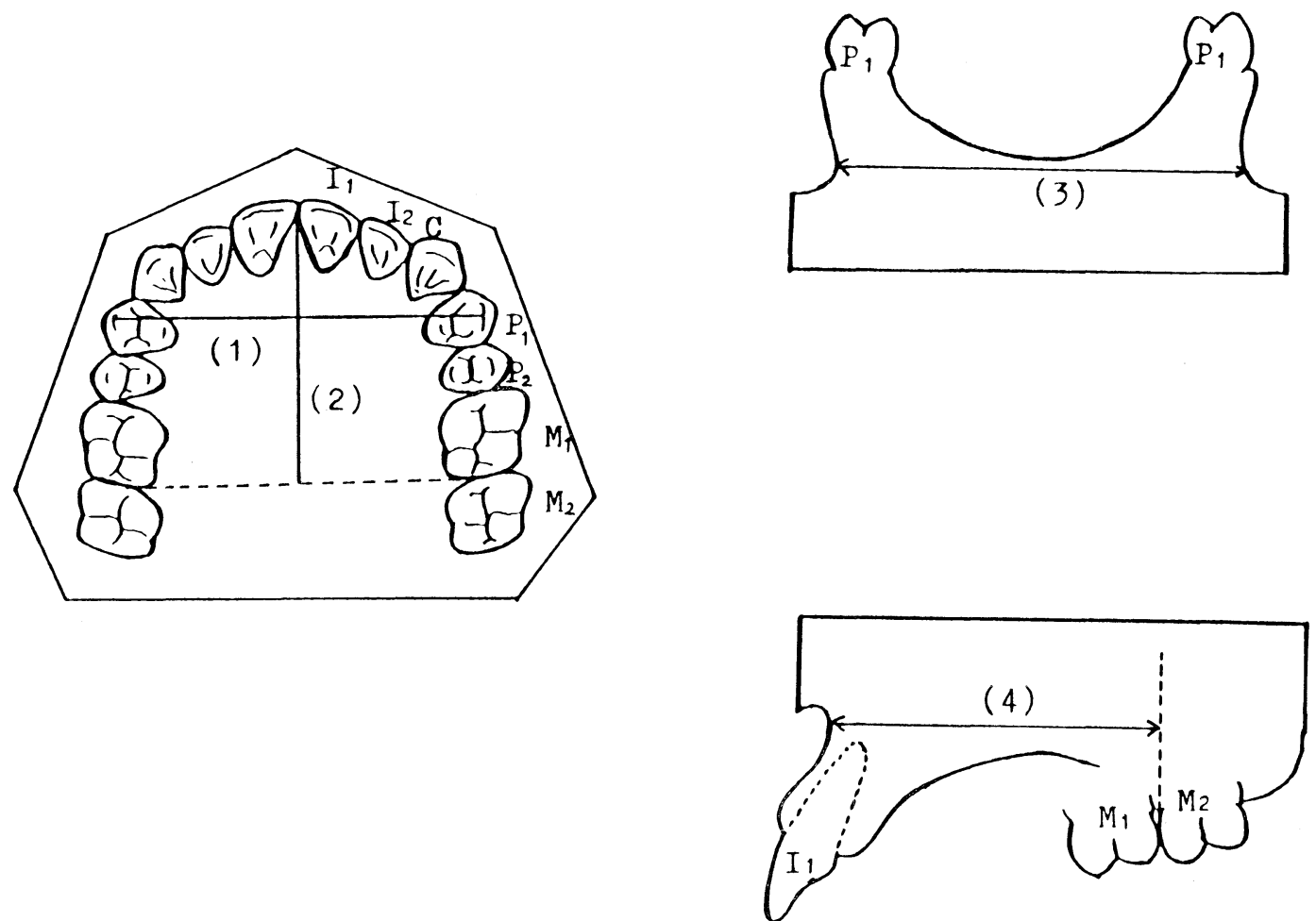

Fig. 1. Model analysis of dental cast;

(1) 1st Bicuspid Coronal Arch Width (C.A.W.)

(2) Coronal Arch Length (C.A.L.)

( 3 ) 1st Bicuspid Basal Arch Width (B.A.W.)

(4) Basal Arch Length (B.A.L.) 


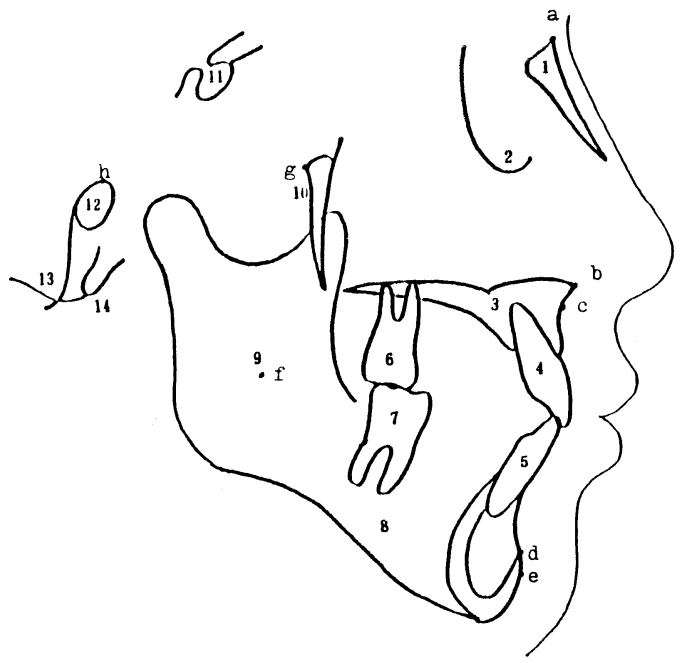

1. nasal bone (a:nasion)

2. orbits

3. palate (b:anterior nasal spina)

4. upper (ce point)

ral incisor

5. lower central incisor

6. upper first molar

7. lower first molar

8. body of mandible (d:supra pogonion)

gonion)

9. ramus of mandible ( $f: X I$ point)

10. pterygomaxillary fissure ( $g$ :pterygoid point)

11. sella turcica

12. external auditory meatus(h:porion)

13. occipital condyle

14. bastion

Fig. 2. a) Anatomical orientation for the analysis of cephalogram

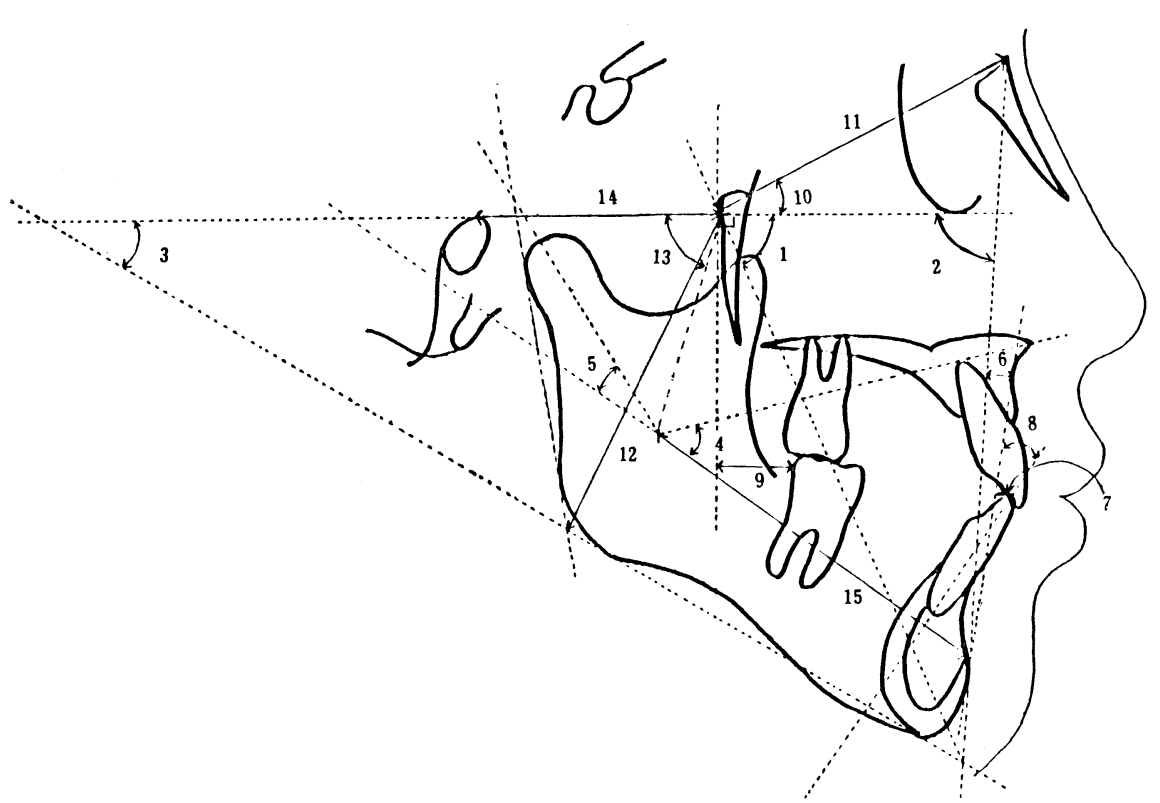

(1) FX

(2) FD

(3) MP

(4) LFH

(5) MA

(6) PTA

(7) TAPo

(8) $\angle$ TAPo

(9) 6 PTV

(10) CD

(11) CLA

(12) PFH

(13) RP

(14) PL

(15) $\mathrm{CL}$

$\leftrightarrow$ distance

$I$ angle

Fig. 2. b) Cephalogram analysis

(1) Facial axis (FX)

(2) Facial depth (FD)

(3) Mandibular plane (MP)

(4) Lower face height (LFH)

(5) Mandibular arc (MA)

(6) Convexity (PTA)

(7) Mandibular incisor protrusion (TAPo)

(8) Mandibular incisor inclination $(\angle \mathrm{TAP})$
(9) Upper molar position (6 PTV)

(10) Cranial deflection (CD)

(11) Cranial length anterior (CLA)

(12) Posterior facial height (PFH)

(13) Ramus position (RP)

(14) Porion location (PL)

(15) Corpus length (CL) 


\section{Method}

At the time they come to our hospital for evaluation of their short stature, oral cavity examinations were performed to check for high arched palate and gingivitis. At the same time, pantomograms were taken to look for the early eruption of permanent teeth, congenital anodontia, malocclusion, microdont and short root. Then, dental casts were made and cephalograms and hand-wrist X-rays were taken. Each tooth crown was measured. The mean of the paired teeth of maxilla and mandible was calculated with a precision of $0.1 \mathrm{~mm}$. The first bicuspid coronal arch width (C.A.W.), coronal arch length (C.A.L.), the 1st bicuspid basal arch width (B.A.W.) and basal arch length (B.A.L.) were also measured using dental cast models according to the method of Ohtsubo (1957) (Fig. 1). Study of the facial morphology was performed by cephalogram analysis as shown in Figure 2 according to the method of Nezu et al. (1984). Dental age and bone-age of hand-wrist were estimated according to the standards of Schour and Massler (1940) and Tanner et al. (1975), respectively. Student's $t$-test, Fisher's exact test and $\mathrm{X}^{2}$ test were used for statistical analyses.

\section{Results}

Oral cavity examination and abnormalities of the teeth

Results of these examinations are shown in Table 1 and 2. Short roots were observed in all patients with Turner's syndrome and one normal short child. Peg shaped teeth were seen in one of 28 Turner's syndrome and 2 of 23 normal short children. Malocclusion was observed in 5 Turner's syndrome and in 4 normal short children. The incidences of malocclusion were $17.9 \%$ and $17.4 \%$, respectively. Therefore there were no differences between the two groups. A high arched palate was observed in 5 Turner's syndrome and in 2 normal short children. The incidence in Turner's syndrome $(17.9 \%)$ is greater than that in normal short children $(8.6 \%)$, but, there is no significant difference between these two values. Gingivitis was seen in $85.7 \%$ of

Table 1. Incidence of tooth abnormalities, high arched palate and gingivitis in patients with Turner's syndrome and in normal short children.

\begin{tabular}{|c|c|c|}
\hline & $\begin{array}{l}\text { Positive Nos of subj. } \\
\text { (percent) }\end{array}$ & Subject No.a \\
\hline \multicolumn{3}{|l|}{ Turner's syndrome $(\mathrm{N}=28)$} \\
\hline Short root & $28(100 *)$ & all subjects \\
\hline Peg shaped tooth & $1(3.6)$ & 24 \\
\hline Malocclusion & $5(17.9)$ & $7,14,18,19,28$ \\
\hline High arched palate & $5(17.9)$ & $14,18,19,20,23$ \\
\hline \multirow[t]{5}{*}{ Gingivitis } & -4 & $10,14,25,27$ \\
\hline & $+\nmid 18$ & $1-5,8,9,11-13,16,17$ \\
\hline & $\left(85.7^{*}\right)$ & $20,21,23,24,26,28$ \\
\hline & $H\} 5$ & $6,7,18,19,22$ \\
\hline & H) 1 & 15 \\
\hline \multicolumn{3}{|c|}{ Normal short children $(\mathrm{N}=23)$} \\
\hline Short root & $1(4.3)$ & 6 \\
\hline Peg shaped tooth & $2(8.6)$ & 10,22 \\
\hline Malocclusion & $4(17.4)$ & $6,11,14,23$ \\
\hline High arched palate & $2(8.6)$ & 14,22 \\
\hline \multirow[t]{3}{*}{ Gingivitis } & -16 & rest of the children \\
\hline & $+\} 4$ & $6,12,15,18$ \\
\hline & Hك $3(30.4)$ & $8,14,21$ \\
\hline
\end{tabular}

\footnotetext{
$* ; \mathrm{p}<0.05$
}

a; Subject No. is the same No. as in Table 2. 
patients with Turner's syndrome, which was greater than that found in normal short children $((30.4 \%)(\mathrm{P}<0.001)$.

Congenital anodontia, dental age and bone age

Results of these studies are shown in Table 2. Early eruption of the teeth (advanced dental age) was observed in 9 patients $(32.1 \%)$ with Turner's syndrome. This incidence did not differ significantly from that found in normal short children (3 sub- jects, 13\%). Congenital anodontia was observed in 16 patients with Turner's syndrome and in 14 normal short children. The incidence of congenital anodontia did not differ significantly between the two groups. Dental age was significantly advanced in Turner's syndrome $(\mathrm{p}<0.05)$. Advanced dental age ranged between one and one and half years with a mean of $1.22 \pm 0.26$ (SD) years.

Bone age was ranged between 8.8 and

Table 2. Bone age, dental age and congenital anodontia in patients with Turner's syndrome and in normal short children

\begin{tabular}{|c|c|c|c|c|c|c|c|c|c|c|c|c|c|}
\hline \multicolumn{6}{|c|}{ Turner's syndrome } & \multicolumn{8}{|c|}{ Normal short children } \\
\hline \multirow{2}{*}{$\begin{array}{l}\text { Subj. } \\
\text { No. }\end{array}$} & \multicolumn{3}{|c|}{ Age (Yr.) } & \multirow{2}{*}{\multicolumn{2}{|c|}{ Conj. anodontia }} & \multirow{2}{*}{$\begin{array}{l}\text { Subj. } \\
\text { No. }\end{array}$} & \multicolumn{3}{|c|}{ Age (Yr.) } & \multirow{2}{*}{\multicolumn{4}{|c|}{ Conj. anodontia }} \\
\hline & $\mathrm{CA}^{-}$ & BA & DA & & & & $\mathrm{CA}$ & BA & DA & & & & \\
\hline 1. & 9.0 & 8.8 & 7 & $8 \mid 8$ & $8 \mid 8$ & 1. & 8.1 & 6.4 & 6 & - & & & \\
\hline 2. & 12.0 & 9.8 & 12 & 8 & & 2. & 8.4 & 6.3 & 8 & - & & & \\
\hline 3. & 12.3 & 11.0 & $13-15$ & $\overline{81}$ & & 3. & 8.5 & 8.5 & 8 & - & & & \\
\hline 4. & 12.3 & 11.4 & $13-15$ & $\overline{18}$ & & 4. & 9.1 & 8.4 & 9 & $8 \mid 8$ & & 2 & \\
\hline 5. & $12 \cdot 8$ & 10.5 & 12 & - & & 5. & 9.2 & 9.3 & 6 & $8 \mid 8$ & & $8 \mid 8$ & \\
\hline 6. & 12.9 & 10.5 & 12 & $8 \mid 8$ & $8 \mid 8$ & 6. & 10.1 & 8.0 & 11 & - & & & \\
\hline 7. & 13.0 & 11.2 & $13-15$ & $\overline{-}$ & & 7. & 10.1 & 9.1 & 10 & $8 \mid 8$ & & & \\
\hline 8. & 13.5 & 11.9 & $13-15$ & - & & 8. & 10.2 & 9.6 & 9 & $8 \mid 8$ & 8 & $8 \mid 8$ & \\
\hline 9. & 13.8 & 13.2 & $13-15$ & - & & 9. & 10.4 & 10.7 & 10 & \begin{tabular}{l|l}
8 & 8
\end{tabular} & $\frac{5}{8}$ & & \\
\hline 10. & 14.4 & 12.2 & $13-15$ & - & & 10. & 10.7 & 9.5 & 11 & 83 & $\begin{array}{ll}32 & 2 \mid 8 \\
\mid\end{array}$ & 8 & $\overline{18}$ \\
\hline 11. & 15.0 & 11.9 & $13-15$ & $8 \mid 78$ & & 11. & 11.0 & 9.7 & 12 & \begin{tabular}{l|l}
8 & 8
\end{tabular} & 8 & & \\
\hline 12. & 15.2 & n.t. & 15 & - & & 12. & 11.0 & 8.6 & 10 & 81 & & & \\
\hline 13. & 15.9 & 12.4 & 15 & $8 \mid 8$ & & 13. & 11.1 & 11.1 & 10 & - & & & \\
\hline 14. & 10.1 & 8.7 & 11 & $\overline{-}$ & & 14. & 11.2 & 8.8 & 11 & - & & & \\
\hline 15. & 10.5 & 9.7 & 12 & $8 \mid 8$ & & 15. & 11.4 & 11.4 & 11 & $8 \mid 8$ & 8 & $\begin{array}{l}8 \mid 8 \\
\end{array}$ & \\
\hline 16. & 11.7 & 10.4 & $13-15$ & - & & 16. & 11.8 & 9.5 & 11 & 8 & & & \\
\hline 17. & 11.8 & 9.0 & $13-15$ & $8 \mid 8$ & & 17. & 12.0 & 10.3 & 12 & E & & & \\
\hline 18. & 12.1 & 10.9 & 12 & $\overline{-}$ & & 18. & 12.1 & n.t. & 12 & 5 & & $2 \mid 2$ & \\
\hline 19. & 13.1 & 10.3 & $13-15$ & $8 \mid 8$ & & 19. & 12.8 & 11.2 & $13-15$ & - & & & \\
\hline 20. & 13.8 & 10.9 & 15 & - & & 20. & 13.1 & 9.6 & 11 & 5 & & 4 & \\
\hline 21. & 13.9 & 10.7 & 15 & $8 \mid 8$ & \begin{tabular}{l|l}
$8 \mid 8$ \\
\end{tabular} & 21. & 13.8 & 11.2 & 11 & 8 & & & \\
\hline 22. & 14.0 & 11.2 & 12 & \begin{tabular}{l|l}
8 & 8 \\
\end{tabular} & $\overline{81 \mid 18}$ & 22. & 13.9 & 10.7 & 12 & \begin{tabular}{l|l}
$8 \mid 8$ \\
8
\end{tabular} & 8 & $8 \mid 8$ & \\
\hline 23. & 14.2 & 12.4 & 15 & $\overline{-}$ & & 23. & 14.8 & 12.0 & $13-15$ & - & & & \\
\hline 24. & 15.0 & 12.7 & 15 & - & & & & & & & & & \\
\hline 25. & 16.8 & 12.4 & 15 & $8 \mid 8$ & & & & & & & & & \\
\hline 26. & 17.0 & 15.0 & 15 & 5 ! & & & & & & & & & \\
\hline 27. & 18.7 & 15.0 & 15 & $8 \mid 8$ & $8 \mid 8$ & & & & & & & & \\
\hline 28. & 21.4 & $>15.0$ & 21 & 8 & & & & & & & & & \\
\hline
\end{tabular}

CA : chronological age, BA: bone age, DA: dental age, n.t.: not tested. 
over 15 years in Turner's syndrome and between 6.3 and 12 years in normal short children. Delayed bone age was observed in both groups. Mean delayed bone age (CA-BA) in Turner's syndrome was $2.1 \pm 1.0$ years, which was greater than that found in normal short children $(1.5 \pm 1.1$ years, $\mathrm{p}<$ 0.05). However, if we calculate the delayed bone age (BA) according to the chronological age $(\mathrm{CA})(\mathrm{CA}-\mathrm{BA} / \mathrm{CA} \times 100)$ there was no significant difference between values found in the two groups $(15.4 \pm 6.3 \%$ vs $13.2 \pm$ $1.9 \%)$. There was no correlation between dental age and bone age.

Tooth size and model analysis of dental cast.

Mean size of each tooth, standard deviation and the maxillary range in patients with Turner's syndrome and in normal short children are shown in Table 3 . The central incisor $\left(\mathrm{I}_{1}\right)$, the first premolar $\left(\mathrm{P}_{1}\right)$, the second premolar $\left(\mathrm{P}_{2}\right)$ and the first molar $\left(\mathrm{M}_{1}\right)$ were significantly smaller in patients with Turner's syndrome than those of normal short children $(p<0.01)$. The size of the lateral incisor $\left(\mathrm{I}_{2}\right)$ and canine $(\mathrm{C})$ were also

Table 3. Tooth size of maxilla in patients with Turner's syndrome and in normal short children

$(\mathrm{mm})$

\begin{tabular}{|c|c|c|c|c|c|c|c|c|c|c|c|c|c|c|}
\hline \multirow[b]{3}{*}{$\mathrm{I}_{1}$} & \multicolumn{7}{|c|}{ Turner's syndrome } & \multicolumn{7}{|c|}{ Normal short children } \\
\hline & \multirow{2}{*}{$\begin{array}{l}N \\
27\end{array}$} & \multirow{2}{*}{$\frac{\mathrm{M}}{8.24^{*}}$} & \multirow{2}{*}{$\begin{array}{l}\text { SD } \\
0.45\end{array}$} & \multirow{2}{*}{$\begin{array}{c}\text { SEM } \\
0.09\end{array}$} & \multicolumn{3}{|c|}{ range } & \multirow{2}{*}{$\begin{array}{l}\mathrm{N} \\
22\end{array}$} & \multirow{2}{*}{$\frac{\mathrm{M}}{8.53}$} & \multirow{2}{*}{$\begin{array}{r}\text { SD } \\
0.51\end{array}$} & \multirow{2}{*}{$\begin{array}{l}\text { SEM } \\
0.11\end{array}$} & \multicolumn{3}{|c|}{ range } \\
\hline & & & & & 7.3 & - & 9.1 & & & & & 7.5 & - & 9.7 \\
\hline $\mathrm{I}_{2}$ & 27 & 6.91 & 0.55 & 0.11 & 5.8 & - & 8.2 & 19 & 6.91 & 0.77 & 0.18 & 4.9 & - & 7.9 \\
\hline $\mathrm{C}$ & 26 & 7.88 & 0.38 & 0.07 & 7.2 & - & 9.0 & 11 & 7.96 & 0.27 & 0.08 & 7.6 & - & 8.6 \\
\hline$P_{1}$ & 24 & $7.16^{* * *}$ & 0.38 & 0.08 & 6.5 & - & 7.9 & 12 & 7.57 & 0.34 & 0.10 & 7.05 & - & 8.15 \\
\hline $\mathrm{P}_{2}$ & 26 & $6.66^{*}$ & 0.47 & 0.09 & 5.7 & - & 7.4 & 11 & 7.07 & 0.60 & 0.18 & 6.30 & - & 8.15 \\
\hline $\mathrm{M}_{1}$ & 27 & $9.64 * * *$ & 0.56 & 0.11 & 8.6 & - & 10.8 & 21 & 10.20 & 0.50 & 0.11 & 9.4 & -1 & 11.1 \\
\hline T.M. & 24 & $93.07^{*}$ & 4.33 & 0.88 & 86.2 & -1 & 102.6 & 8 & 97.46 & 3.18 & 1.13 & 93.6 & -10 & 02.1 \\
\hline C.A.W. & 25 & 41.41 & 1.81 & 0.36 & 38.0 & - & 44.7 & 12 & 40.11 & 2.96 & 0.85 & 34.8 & -4 & 43.7 \\
\hline C.A.L. & 27 & $36.88 * *$ & 2.63 & 0.51 & 31.8 & - & 42.6 & 21 & 38.77 & 2.31 & 0.50 & 35.9 & - & 44.8 \\
\hline B.A.W. & 25 & 45.90 & 1.87 & 0.37 & 42.4 & - & 49.15 & 7 & 45.33 & 3.43 & 1.30 & 40.4 & - & 49.2 \\
\hline B.A.L. & 25 & 33.27 & 2.48 & 0.50 & 28.7 & - & 37.7 & 10 & 34.59 & 2.01 & 0.64 & 31.8 & - & 37.8 \\
\hline
\end{tabular}

Table 4. Tooth size of mandibula in patients with Turner's syndrome and in normal short children

$(\mathrm{mm})$

\begin{tabular}{|c|c|c|c|c|c|c|c|c|c|c|c|c|c|}
\hline \multirow[b]{3}{*}{$\mathrm{I}_{1}$} & \multicolumn{7}{|c|}{ Turner's syndrome } & \multicolumn{6}{|c|}{ Normal short children } \\
\hline & \multirow{2}{*}{$\begin{array}{l}\mathrm{N} \\
27\end{array}$} & \multirow{2}{*}{$\frac{M}{5.26^{*}}$} & \multirow{2}{*}{$\begin{array}{l}\text { SD } \\
0.40\end{array}$} & \multirow{2}{*}{$\begin{array}{c}\text { SEM } \\
0.08\end{array}$} & \multicolumn{3}{|c|}{ range } & \multirow{2}{*}{$\frac{N}{22}$} & \multirow{2}{*}{$\begin{array}{c}\mathrm{M} \\
5.52\end{array}$} & \multirow{2}{*}{$\begin{array}{r}\text { SD } \\
0.38\end{array}$} & \multirow{2}{*}{$\begin{array}{c}\text { SEM } \\
0.08\end{array}$} & \multicolumn{2}{|c|}{ range } \\
\hline & & & & & 4.4 & - & 6.0 & & & & & $4.55-$ & 6.25 \\
\hline $\mathrm{I}_{2}$ & 26 & $5.78^{* * *}$ & 0.31 & 0.06 & 5.3 & - & 6.4 & 20 & 6.16 & 0.36 & 0.08 & $5.45-$ & 6.85 \\
\hline $\mathrm{C}$ & 26 & 6.72 & 0.47 & 0.09 & 6.0 & - & 7.8 & 15 & 6.82 & 0.45 & 0.11 & $6.0-$ & 7.4 \\
\hline$P_{1}$ & 25 & 7.16 & 0.42 & 0.08 & 6.3 & - & 8.2 & 13 & 7.30 & 0.56 & 0.15 & $6.45-$ & 8.15 \\
\hline $\mathrm{P}_{2}$ & 25 & 6.88 & 0.51 & 0.10 & 5.7 & - & 7.8 & 10 & 7.12 & 0.54 & 0.17 & $6.35-$ & 8.0 \\
\hline $\mathrm{M}_{1}$ & 26 & $10.33 * * *$ & 0.55 & 0.11 & 9.2 & - & 11.65 & 21 & 10.99 & 0.53 & 0.12 & $9.8-$ & 11.7 \\
\hline M.T. & 22 & 84.25 & 4.46 & 0.95 & 76.4 & - & 92.6 & 8 & 87.61 & 4.20 & 1.48 & $80.3-$ & 93.9 \\
\hline C.A.W. & 25 & $35.02 * * *$ & 1.44 & 0.29 & 31.3 & - & 37.3 & 10 & 32.99 & 2.49 & 0.79 & $29.35-$ & 35.9 \\
\hline C.A.L. & 26 & $31.69 * * *$ & 2.09 & 0.41 & 27.0 & - & 35.4 & 21 & 35.89 & 2.87 & 0.63 & $31.65-$ & 41.2 \\
\hline B.A.W. & 23 & 40.51 & 2.49 & 0.52 & 31.6 & - & 44.8 & 5 & 37.91 & 3.64 & 1.63 & $32.65-$ & 42.9 \\
\hline B.A.L. & 24 & 31.61 & 2.66 & 0.54 & 24.8 & - & 35.8 & 8 & 34.86 & 3.11 & 1.10 & $30.8-$ & 38.7 \\
\hline
\end{tabular}


smaller in patients with Turner's syndrome; however, there was no significant difference between the two groups. However, when totalled (Tooth Material; $\mathrm{I}_{1}+\mathrm{I}_{2}+\mathrm{C}+\mathrm{P}_{1}+\mathrm{P}_{2}$ $+\mathrm{M}_{1}$ ), the mean size of $93.1 \pm 4.3 \mathrm{~mm}$ was significantly smaller than that of normal short children $(\mathrm{m}=97.5 \pm 3.2, \mathrm{p}<0.05)$. By model analysis, coronal arch length (C.A.L.) was significantly greater $(\mathrm{p}<0.01)$ in Turner's syndrome, but coronal arch width (C.A.W.), basal arch width (B.A.W.) and basal arch length (B.A.L.) did not differ significantly

Table 5. Cephalogram analysis in patients with Turner's syndrome and in normal short children (NSC)

\begin{tabular}{|c|c|c|c|c|c|c|c|}
\hline \multicolumn{2}{|c|}{ Age Group } & \multicolumn{2}{|c|}{ 9-10 yr. } & \multicolumn{2}{|c|}{$11-12$ yr. } & \multicolumn{2}{|c|}{ 13-14 yr. } \\
\hline \multirow{2}{*}{\multicolumn{2}{|c|}{$\mathrm{N}$}} & Turner & NSC & Turner & NSC & Turner & NSC \\
\hline & & $\overline{(3)}$ & $\overline{(9)}$ & $\overline{(11)}$ & $\overline{(8)}$ & $\overline{(7)}$ & (4) \\
\hline $\mathrm{Fx}$ & (degree) & $84.8 \pm 4.0$ & $87.5 \pm 7.9$ & $87.9 \pm 2.2$ & $87.3 \pm 3.7$ & $86.3 \pm 4.0$ & $84.9 \pm 2.1$ \\
\hline FD & (de & $82.3 \pm 1.2$ & $86.0 \pm 5.2$ & $86.9 \pm 1.4$ & $85.6 \pm 2$ & $86.1 \pm 4.3$ & $85.8 \pm 3.7$ \\
\hline MP & (deg & $33.5 \pm 5.0$ & $31.3 \pm 7.5$ & $27.9 \pm 2.6$ & $30.5 \pm 3$ & $26.3 \pm 6.5$ & $29.9 \pm 5.4$ \\
\hline LFH & (deg & $53.1 \pm 4.8$ & $51.7 \pm 7.3$ & $49.6 \pm 3.1$ & $48.7 \pm 3.3$ & $48.7 \pm 3.6$ & $53.2 \pm 4.6$ \\
\hline MA & (deg & $29.2 \pm 9.1$ & $27.2 \pm 5.1$ & $29.4 \pm 4.2$ & $28.5 \pm 4.9$ & $33.2 \pm 5.5$ & $30.2 \pm 5.6$ \\
\hline PTA & $(\mathrm{mn}$ & $6.3 \pm 1.8$ & $3.5 \pm 3.3$ & $3.2 \pm 1.9$ & $4.6 \pm 2.1$ & $3.1 \pm 3.3$ & $5.6 \pm 2.3$ \\
\hline TAPo & $(\mathrm{mm})$ & $5.9 * * * \pm 1.9$ & $3.7 \pm 3.3$ & $3.9 \pm 2.4$ & $3.9 \pm 1.5$ & $4.4 \pm 3.0$ & $5.2 \pm 2.3$ \\
\hline$\angle \mathrm{TAPo}$ & o (degree) & $23.3 \pm 7.1$ & $24.5 \pm 7.7$ & $28.2 \pm 7.0$ & $24.3 \pm 3.7$ & $26.5 \pm 7.5$ & $23.9 \pm 4.8$ \\
\hline 6 PTV & $(\mathrm{mm})$ & $11.4 \pm 3.4$ & $11.7 \pm 6.3$ & $15.5^{* *} \pm 2.4$ & $11.6 \pm 3.3$ & $5.6 \pm 4.2$ & $15.6 \pm 3.1$ \\
\hline $\mathrm{CD}$ & (de & $24.8 \pm 1.2$ & $27.2 \pm 2.3$ & $27.6 \pm 1.7$ & $27.2 \pm 2.0$ & $8.5 \pm 3.2$ & $28.2 \pm 2.0$ \\
\hline CLA & $(\mathrm{mm}$ & $54.6 \pm 1.2$ & $54.7 \pm 2.5$ & $57.2 \pm 3.5$ & $57.6 \pm 2.6$ & $59.3 * \pm 3.2$ & $54.3 \pm 1.7$ \\
\hline PFH & $(\mathrm{mm})$ & $58.9 \pm 4.9$ & $54.4 \pm 2.4$ & $60.7 \pm 3.9$ & $57.3 \pm 3.8$ & $64.6 \pm 4.2$ & $58.3 \pm 5.4$ \\
\hline $\mathrm{RP}$ & (degr & $72.9 \pm 3.2$ & $79.2 \pm 5.8$ & $76.5 \pm 3.4$ & $77.6 \pm 4.4$ & $76.1 \pm 2.6$ & $77.0 \pm 1.4$ \\
\hline PL & (degre & $39.7 * \pm 1.1$ & $35.3 \pm 3.1$ & $37.4 \pm 4.3$ & $38.6 \pm 3.2$ & $38.8 \pm 3.8$ & $35.4 \pm 3.4$ \\
\hline $\mathrm{CL}$ & $(\mathrm{mm})$ & $60.6 \pm 2.1$ & $59.7 \pm 4.4$ & $64.3 \pm 3.3$ & $63.5 \pm 2.2$ & $64.3 \pm 3.6$ & $61.8 \pm 3.8$ \\
\hline
\end{tabular}

Table 6. Normal values for each factor in cephalogram analysis; normal values at age 9 of Japanese children are shown.

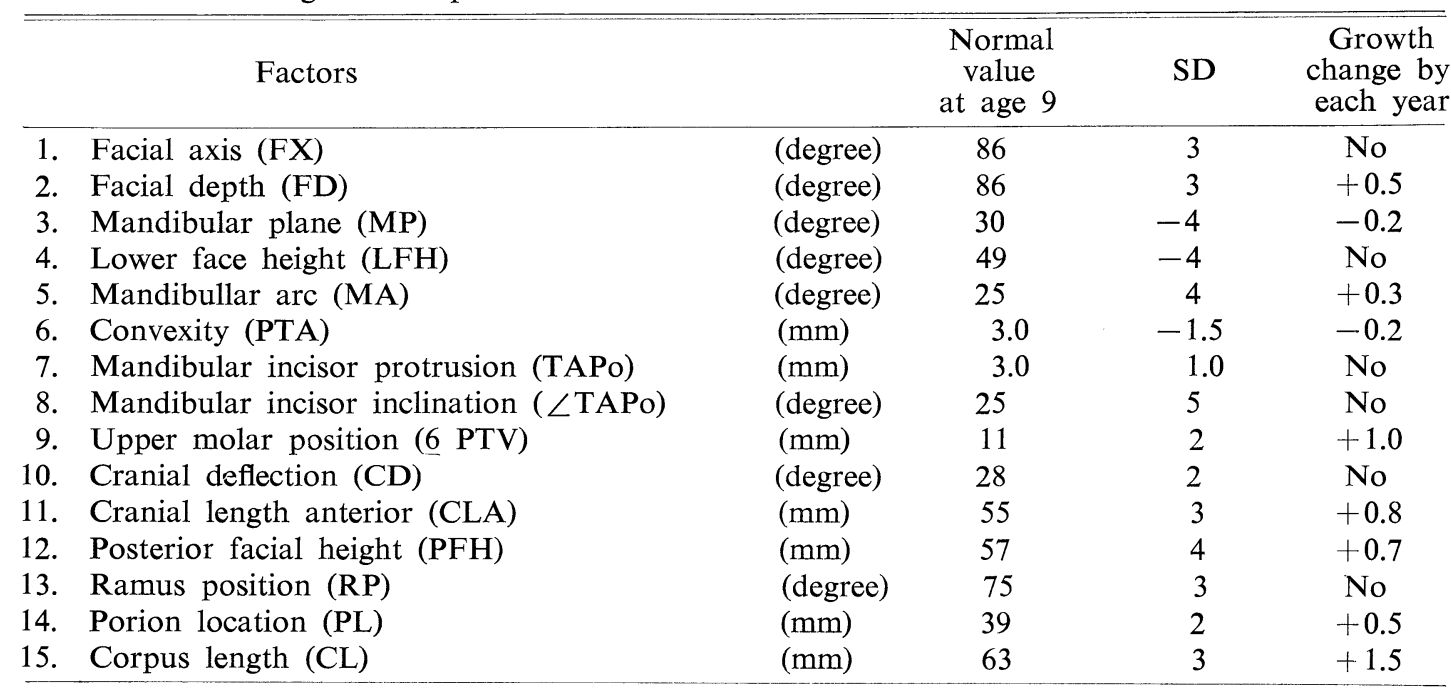


between the two groups.

The mean size of each tooth, standard deviation and its mandibular range in patients with Turner's syndrome and in normal short children are shown in Table 4. The central incisor $\left(I_{1}\right)$, lateral incisor $\left(I_{2}\right)$ and the first molar $\left(\mathrm{M}_{1}\right)$ were significantly smaller in patients with Turner's syndrome than in normal short children $(\mathrm{p}<0.05)$. The canine $(C)$, and the first and second premolars $\left(\mathrm{P}_{1}\right.$ and $\left.\mathrm{P}_{2}\right)$ were smaller in patients with Turner's syndrom; however, there was no significant difference between the two groups. When totalled (Tooth Material) the mean size of $84.3 \pm 4.5 \mathrm{~mm}$ was smaller than that of normal short children $(\mathrm{m}=87.6 \pm 4.2 \mathrm{~mm})$; however; these two values did not differ significantly either. By model analysis, coronal arch width (C.A.W), coronal arch length (C.A.L.) and basal arch length (B.A.L.) were significantly different between the two groups $(\mathrm{p}<0.01)$.

\section{Cephalogram analysis}

Cephalogram analysis in patients with Turner's syndrome and in normal short children is shown in Table 5. Some of these parameters change in an age-dependent manner up to 15 years (Table 6). However, because of the lack of large numbers of subjects in each age group, we classified our subject into 2 year groups. Only a few of the subjects are found in the 11 and 12 age group. Of the 15 factors examined, only 6 PTV differed significantly between the patients with Turner's syndrome and normal short children.

\section{Discussion}

We investigated the orofacial structures in patients with Turner's syndrome and compared them to those in normal short children. High arched palate, peg shaped tooth, malocclusion and congenital anodontia have been reported as characteristic of
Turner's syndrome (Haddad and Wilkins 1959, Lemli and Smith 1963 Nishikawa et al., 1969, Horowitz and Morishima 1974); however, we did not find any greater incidence than in normal short children. We diagnosed high arched palate subjectively by using dental casts. As there are no definite criteria for high arched palate, the incidence might depend upon the investigator. Peg shaped tooth, malocclusion and congenital anodontia are not characteristic findings in our patients with Turner's syndrome. The short root was seen in all patients with Turner's syndrome.

Surprisingly, we found gingivitis in $85.7 \%$ with the Turner's syndrome patients. This incidence is greater than that found in normal short children. There are some reports that estrogens, progestins and/or androgens may induce proliferation of gingival epithelium (Litwack et al., 1970, Fukuda 1971, Michaelides 1981). Some of our subjects had been treated with estrogen and anabolic steroid together with or without hGH. Therefore we have done a statistical analysis to determine whether these treatments were the cause of gingivitis. Treatment with hGH had been performed in 21 patients with Turner's syndrome and in 3 normal short children. There are no significant differences in the incidence of gingivitis between the two groups who were treated with hGH. However, in non-hGH-treated subjects, the incidence of gingivitis is greater in Turner's syndrome than in normal short children $(p<0.05)$. On the effect of estrogen and anabolic steroid with or without hGH treatment in Turner's syndrome, we found no significant difference in the incidence of gingivitis and these hormones treated. These data indicate that gingivitis has no relationship to $\mathrm{hGH}$, estrogen and anabolic steroid treatments. We simply think that the lack of tooth brushing is the cause of gingivitis in these patients.

Early eruption of permanent teeth has been reported in Turner's syndrome (Skingu 
1962, Gorlin 1963, Doner et al., 1967). We also found early eruption of the teeth in 9 Turner's patients; however, the incidence is not statistically significant from that of normal short children. The tooth sizes of the maxilla and mandible are, on the whole, smaller in Turner's syndrome, although not all teeth showed significant differences. It is well known that the permanent teeth appear at 4 months of fetal age (Kurosu 1981). When the shape of the crown is completed, the eruption of the crown begins in accordance with the formation of the root. The complete formation of the root is 5-7 years after the crown formation and/ or 1-2 years after crown eruption. Therefore, the early eruption of the teeth (advanced dental age) found in Turner's patients might have some correlation to their short root.

The coronal arch width (C.A.W.) and basal arch width (B.A.W.) are longer and the coronal arch length (C.A.L.) and basal arch length (B.A.L.) are shorter in patients with Turner's syndrome, indicating underdevelopment of the mandible in the forward direction, which results in the wide shaped face of the Turner's patient, We have compared these parameters with those in normal children reported by Otsubo (1957). Each parameter is greater in our normal short children, indicating the development of orofacial region during these 23 years. We did not find any characteristics peculiar to Turner's patients by cephalogram.

\section{Acknowledgements}

This research was partly supported by Grants in Aid for the Foundation for Growth Science and Memorial Foundation of Dr. Itoe Okamoto.

\section{References}

Doner, J. H., A. Finkelman and R. Soricelli (1967). Turner's syndrome. Oral. Surg. Oral.
Med. Oral. Pathol. 24, 27-32.

Filipsson, R., J. Lindsten and S. Almqvist (1965). Time of eruption of the permanent teeth, cephalometric and tooth measurement and sulphation factor activity in forty-five patients with Turner's syndrome with different types of $\mathrm{X}$ chromosome aberration. Acta. Endocrinal., 48, 91-113.

Fukuda, H. (1971). Experimental studies on the effects of sex hormones on the proliferation of cells derived from the gingival tissues in tissue culture (in Japanese). Shika Gakuho. 71, 12141232.

Gorlin, R. (1963). Chromosomal abnormalities and oral anomalies. J. Dent. Res. (supple). 42, 1297-1306.

Grumbach, M. and F. A. Conte (1981). Disorders of sex differentiation. In: Textbook of Endocrinology (eds. R. H. Williams), the 6th ed., Igaku-Shoin/Saunders, Japan. pp. 456-458.

Haddad, H. M. and L. Wilkins (1959). Congenital anomalies associated with gonadal aplasia. Pediatrics. 23, 885-902.

Horowitz, S. L. and A. Morishima (1974). Palatal abnormalities in the syndrome of gonadal dysgenesis and its variants and in Noonan's syndrome. Oral. Surg. 38, 839-844.

Kurosu K. (1981). Dental development and disturbance (in Japanese). In: Gendai-Shoni Shikagaku, Ishiyakushuppan, Tokyo, pp. 65-81.

Lemli, L. and D. W. Smith (1963). The XO syndrome: A study of the differentiated phenotype in 25 patients. Pediatrics. 63, 577-588.

Litwack, D., J. E. Kennedy and H. A. Zander (1970). Response of oral epithelia to ovariectomy and estrogen replacement. J. Periodont. Res. 5, 263-268.

Michaelides, P. L. (1981). Treatment of periodontal disease in a patient with Turner's syndrome. A case report. J. Periodontol. 52, 386-389.

Nezu, H., K. Nagata, Y. Yoshida and M. Kikuchi (1984). Bioprogressive diagnosis of Orthodontia (in Japanese). Rocky Mountain Morita, Tokyo.

Nishikawa, M., T. Fujisawa., Y. Kakiuchi and M. Tsuboniwa (1969). Turner's syndrome in clinical medicine (in Japanese). Naika (Inter Med.). 23, 155-160.

Otsubo, J. (1957). The relation among width of dental crown, coronal arch and basal arch in adult Japanese with normal occlusion (in Japanese). J. Jpn. Orthod. Soc. 16, 36-46. 
Schour, I. and M. Massler (1940). Studies in tooth development: The growth pattern of human teeth (part II). J. Am. Dental. Assoc. 27, 1918-1931.

Shingu, H. (1926). Deformities of skeleton in Turner's syndrome (in Japanese). Orthop. Surg. 13, 199-204.

Takano, K., N. Hizuka and K. Shizume. Treat- ment of Turner's syndrome with methionyl human growth hormone. Acta. Endocrinal. $(C P H)$ 1986, in press.

Tanner, J. M., R. H. Whitehouse, W. A. Marshall, M. J. R. Healy and H. Goldstein. Assessment of Skeletal Maturity and Prediction of Adult Height (TW 2 Method). Academic Press INC., London 1975. 